\title{
Research of Management Tools and Techniques of Social Media Marketing Time Based on Mathematical and Empirical Analysis
}

\author{
Yu Cao \\ Wuhan Donghu University \\ Wuhan, China \\ 50699788@qq.com
}

\begin{abstract}
Objective:The life of the people in the 21st century is full of advanced science and technology and the internet media, a wealth of information and technology acquisition, fast tools and change in service; these are giving birth to the era revolution of social media marketing. 2.Methods:This paper focused on the development trend of social media era, had public opinion analysis of social media of internet era, contacted social actuality and had depth analysis of background and advantages skills of social media marketing, then based on this to have function relationships mathematical empirical of time management tools of social media marketing, and tried to find opportunity for change and development of the strategic decision-making of social media marketing. 3.Results:In summary, it needs to accurately reflect the laws of marketing and social requirement, uses replying, forwarding, reviews and other ways to concern friends, and establishes a truly reliable social media marketing model. 4.Conclusion: We have to seize the opportunities of development, and be good at using mathematical law and the statistical empirical analysis in the increasingly developed social media era, grasp the time management tools and techniques for social media marketing, and actively make social media marketing create new value.
\end{abstract}

Keywords-Mathematical empirical; social media; marketing; time management; skills research

\section{INTRODUCTION}

During the past two decades, information and communication technology largely influenced and changed the way of our life and social relations, there is no doubt that we chat, work or participate in recreational activities are closely linked with communication[1]. The average and weekly time of U.S. Internet users using the network was 10 hours in 2001, after 10 years, the average time that U.S. Internet users using the network per week will increase to 16 hours. People in long-term use the Internet applications, also improve the operation of the computer skills and more convenient to access the information and data required, greatly improve the efficiency of work and study, and also indicates that the era revolution of social media marketing has come.

\section{PUBLIC OPINION ANALYSIS OF SOCIAL MEDIA IN INTERNET ERA}

So far from the beginning of the 21 st century, we have been living in the era of social media, in the situation of facing a lot of free and easy application program and tools, when we need it we have to spend a lot of time to choose similar applications. Internet users use a variety of applications and tools to achieve each objective and complete the necessary requirements; this is a huge change and help of the media for the social life in the $21 \mathrm{st}$ century[2].

The number of global Internet users presents a rising trend, the number of Internet users around the world in 2007 was 2.7 billion, rose to 1.1 billion by the end of 2011 , in the first nine months of 2012, the number of the global Internet user climbed to 2.1 billion, the growth of global mobile Internet users is growing at a rapid gesture, mobile traffic of mobile Internet users has accounted for $13 \%$ of the overall traffic of the Internet, and however, it was only $1 \%$ in 2009 . We find that more and more Internet users are using mobile devices and the Internet in real society, their number has gone far beyond the traditional broadband Internet users, the data released by the China Internet Network Information Center (CNNIC) in July represents that $60 \%$ of China's Internet users use the Internet through mobile devices, such as mobile phones, MID, Tablet PC and so on.

\section{BACKGROUND AND ADVANTAGE TECHNIQUE ANALYSIS OF SOCIAL MEDIA MARKETING}

In the Internet era, especially after application and promotion of the second generation of Internet technology, and from the wealth of information provided by the 
Internet, people generally believe that the network is a platform to meet people's daily application and a place to communicate with each other. In addition, in the application program that developed based the second generation of Internet, sharing, social networking, collaboration and other elements have a great attraction for the network users. As of 2003, in the Internet society every other day it was to produce the amount of information so far as the equivalent of human civilization creation[3].

According to the statistics of global Internet development report of the Swedish Internet market research firm, in 2011 the number of global Internet users was 2.1 billion; the number of SNS account was 2.4 billion.

In the Royal Pingdom2011 global Internet industry development report, it collected a large amount of data of e-mail, web site, network server, domain names, Internet users, social media, mobile, video, picture, webpage browser and other respects in 2011. It can be seen in the following table.

As shown in Table 1, part of the social media users of global Internet are active, in order to achieve more convenient operability of Internet application program, it meets the needs of more users, social networking sites have emerged with new features and integration of more advanced technology. The user has become a "producer" of these sites; their original content are uploaded to the site and accessed and shared by other users, the information is spread quickly and widely[4]. Therefore, freedom of speech and the way of showing self will soon be accepted by the public or even sought after, Internet users upload and quickly share new content, this promotes the progress of the entertainment industry, computer technology, as well as the search function, and further provides a broad space for social media marketing.

\section{TABLE I. GLOBAL INTERNET PART OF THE SOCIAL MEDIA DATA STATISTICS}

(Source: Royal Pingdom2011 the global Internet industry development report)

\begin{tabular}{|l|c|l|}
\hline Name & $\begin{array}{l}\text { Quantit } \\
\text { y } \\
\text { (million }\end{array}$ & \multicolumn{1}{|c|}{ Specific } \\
\hline E-mail & 314. & $\begin{array}{l}\text { The number of global e-mail } \\
\text { account }\end{array}$ \\
\hline $\begin{array}{l}\text { websit } \\
\text { e }\end{array}$ & 5.55 & $\begin{array}{l}\text { The number of sites (December } \\
\text { 2011) }\end{array}$ \\
\hline $\begin{array}{l}\text { Domai } \\
\text { n name }\end{array}$ & 2.2 & $\begin{array}{l}\text { As of the third quarter of 2011, the } \\
\text { number of registered domain name }\end{array}$ \\
\hline $\begin{array}{l}\text { Interne } \\
\text { t users }\end{array}$ & 21 & $\begin{array}{l}\text { The total number of Internet users } \\
\text { worldwide }\end{array}$ \\
\hline $\begin{array}{l}\text { Social } \\
\text { media }\end{array}$ & 24 & $\begin{array}{l}\text { The number of global social } \\
\text { networking account }\end{array}$ \\
\hline
\end{tabular}

\begin{tabular}{|l|c|l|}
\hline Mobile & 59 & $\begin{array}{l}2011 \text { the number of mobile } \\
\text { subscribers worldwide estimates }\end{array}$ \\
\hline Video & 1000 & \multicolumn{1}{|c|}{ Video Views on YouTube } \\
\hline Picture & 1000 & $\begin{array}{l}\text { The number of images hosted by } \\
\text { Flickr (August 2011) }\end{array}$ \\
\hline
\end{tabular}

Social Media Marketing is essentially a way of chatting, sharing, participating in interactive through the network of online marketing activities. It can be shared through a variety of forms, such as text, images, sound and video. Technology of such sites includes: blogs, message boards, entries resolution, and allows the user to communicate and have various forms of interaction. The social media marketing process should notice the following tips, focus on the social media marketing social media features has to pay attention to the six core principles of the value, the specific is shown in Figure 1.

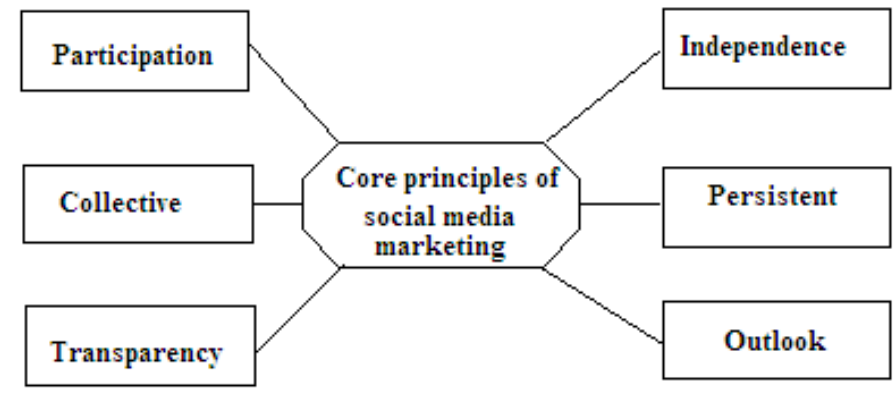

Figure 1. Core principles of social media marketing

As shown in Figure 1, the core of social media marketing techniques is to pay attention to the six core principles of social media marketing, they are: participation, collective, transparency, independence, persistence, and prospects. The participation means dissemination of all kinds of information of social media marketing, it is achieved through mutual exchanges and joint participation between the users, it is dependent on a wide range of links to exist, all kinds of marketing tools and content are widely broadcasted during the extensive use of users and sharing of link, in order to achieve marketing effectiveness; collective concern means all types of information in a lot of social media marketing, collected information are edit and processed to republish, at the same time obtains more complete data and information through cloud-sharing from the networks; transparency means maintaining the authentic participation of the social media marketing information in the network, it has strong transparency; independence refers users to participation in interactive, social media marketing platform has sufficient independence; persistence means strict constraints of the action of social media marketing in the online world, it pays attention to the reputation on the Internet; prospects means the social media marketing will become bright star in the digital life, it will become more familiar and used by more people, and always has characteristics to make people have social contacts, in order to accurately grasp the dynamic of social media marketing[5]. 
IV. FUNCTIONAL RELATIONSHIPS EMPIRICAL OF TIME MANAGEMENT TOOLS OF SOCIAL MEDIA MARKETING

Social Media Marketing needs to pay attention to another unique feature of the social media, it will link the released contents to other sites, the resources are obtained by more people.

The choice for our social media marketing forms new opportunities, it should pay attention to the function and relationship processing of social media marketing time management tools during the actual marking, so as to achieve the ideal state of marketing, such as the analysis of market demand, focus on demand impact factor, such as marketing time (special date anniversary), selection tools (such as social networking sites, micro blogging, blogs, chat software and so on), and its actual function relationships impact factor, the mathematical expression can be built between them , namely[6]:

$$
q_{i}=f\left(I, p_{1}, \ldots, p_{i}, \ldots, p_{n}\right)
$$

In equation (1), ${ }^{q_{i}}$ is the society demand forecast for social media marketing commodity, I is for the marketing time, $p_{1}, \ldots, p_{i}, \ldots, p_{n}$ are the select tools, $\mathrm{n}$ is commodity price of social media marketing. In the actual process, marketing time and marketing tools are the mainly impact of social media marketing efforts, specific marketing products can establish a new function to analyze the relationship between them, such as the spending habits of consumers, life of marketing product and so on, the derivation of the demand function is as follows: $x=(x 1, x 2, \ldots, x n)$ is a combination(vector) of a social media marketing tools, $\mathrm{p}=(\mathrm{p} 1, \mathrm{p} 2, \ldots, \mathrm{pn})$ means the commodity corresponds marketing time. Through $\min . p x$,

formula s.t $: U-U(x)=0$ and $\mathrm{M}-\mathrm{px}=0$, we can solve relationship between $\mathrm{P}$ and $\mathrm{M}$ and best demand quantity of goods combination of social media marketing merchandise[7]:

$$
x=\left[\begin{array}{c}
x_{1} \\
\vdots \\
x_{n}
\end{array}\right]=\left[\begin{array}{c}
\varphi_{1}(p, M) \\
\vdots \\
\varphi_{n}(p, M)
\end{array}\right]=\varphi(p, M)
$$

The above formula uses the formula $\min \cdot p x$,

s.t : $U-U(x)=0$ and $\mathrm{UU}(\mathrm{x})=0$, it can solve function relationship between the selected combination $\mathrm{x} 1$ of the social media marketing tool and $\mathrm{p}, \mathrm{U}$ : $x_{i}=\varphi(p, U)$ formula $\frac{\partial u}{\partial x_{i}}=p_{i} \lambda \quad, \quad i=1, \cdots, n$ is called the Alex demand of the $\mathrm{i}$-th social media marketing merchandise, if the price becomes $\mathrm{p}$ to $p^{\prime}$, the total effect of the $\mathrm{i}$-th social media marketing items is[8]: $\varphi\left(p^{\prime}, M\right)-\varphi(p, M)$
The substitution

effect

is:

$\varphi\left(p^{\prime}, U(\varphi(p, M))\right)-\varphi(p, M)$

Income effect is[9]: $\varphi\left(p^{\prime}, M\right)-\varphi\left(p^{\prime}, U(\varphi(p, M))\right)$

In summary, it can reflect the impact relationship between each variable in the marketing process, and it can be used in the structural analysis and decision prediction of social media marketing[10].

\section{CONCLUSION}

The innovation and every change of social media can quietly change people's minds and habits when people are reading and sharing news, information. Living in the information age, we have to seize the opportunities of development, and be good at using mathematical law and the statistical empirical analysis in the increasingly developed social media era, grasp the time management tools and techniques for social media marketing, and actively make social media marketing create new value.

\section{REFERENCES}

[1] Li Bingyang. Principles and key issues of good social media marketing[J].Management \& Technology of SMEs, 2011 (2):3741.

[2] Zhang Wenge. Zhao Chuang. Concerned about social media marketing to grab marketing 3.0 opportunities [J]. The world telecommunication, 2011 (7):56-58.

[3] Fu Yuhui. Social media: certainty and uncertainty in future [J].Internet World, 2011 (9):27-29

[4] Deng Yu, Tang Dalin, Yu Meng. Brand marketing road in the era of social media [J].Modern Marketing, 2011 (11):8-11

[5] Tang Xingtong. Trend of social media marketing--strategies and methods [M].Beijing,:Tsinghua University Press, 2011:255-268.

[6] Lin Yue. Social marketing strategy in era of mobile Internet [J].Information networks, 2009(6):91-93,26

[7] Mei Qinghao. Marketing management [M].Renmin University of China Press, 2011:464-475.

[8] ZhaoQili.Applied research report of social networking sites of Internet users in China in 2011 [M].Qingdao University Press, 2012:313-319.

[9] L. Malita and C. Martin, Digital Storytelling as Web Passport to Success in the 21 st Century[C]. Procedia - Social and Behavioral Sciences, 2010:1158-1167.

[10] http://dgwanfangdata.com.cn/Periodical_xiandaiyx201111009.aspx 